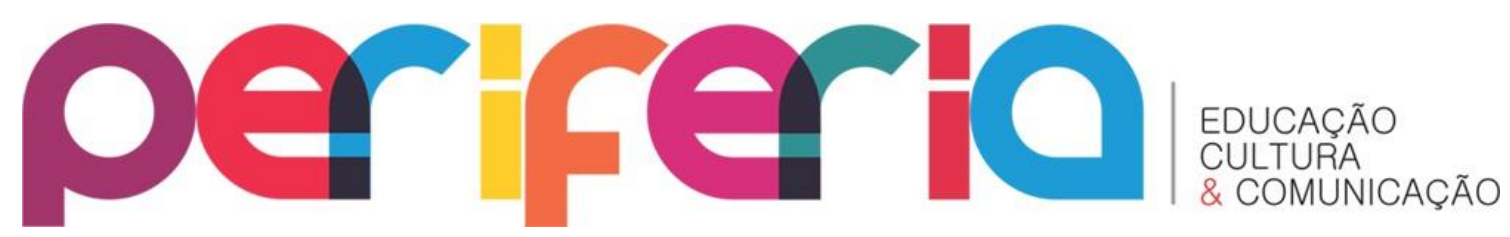

\title{
O DISCURSO, O PODER E AS REPRESENTAÇÕES DE NOVA IGUAÇU
}

\author{
Everaldo Lisboa dos Santos ${ }^{1}$ \\ Universidade Castelo Branco \\ Secretaria de Estado de Educação
}

\section{RESUMO}

As imagens relacionadas à Baixada Fluminense e ao município de Nova Iguaçu, recorte espacial deste artigo, são quase sempre representadas pelos discursos como lócus de segmentos de baixa renda e precariedade de infraestrutura e diversas mazelas sociais. No entanto, elas são confrontadas por novas representações que destacam as belezas naturais, o patrimônio histórico, o poder aquisitivo da população local, os novos empreendimentos imobiliários etc., modificando assim parcialmente no imaginário popular a ideia de atraso social, econômico e cultural do município iguaçuano.

Palavras-chave: Nova Iguaçu, Discurso, Novas representações.

\section{THE DISCOURSE, THE POWER AND THE REPRESENTATIONS OF NOVA IGUAÇU} \section{ABSTRACT}

Images related to Baixada Fluminense and the municipality of Nova Iguaçu, spatial approach of this article, are almost always represented by the discourse as the locus of low-income segments and precarious infrastructure and various social ills. However, these are confronted by new representations that highlight the natural beauty, historical heritage, the purchasing power of the local population, new property developments etc., partially modifying thus the popular imagination the idea of social backwardness, economic and cultural iguaçuano the municipality.

Keywords: Nova Iguaçu, discourse, new representations.

\section{INTRODUÇÃO}

No cenário contemporâneo emergem novas representações da periferia metropolitana do Rio de Janeiro e, particularmente, de Nova Iguaçu, recorte espacial deste artigo. As novas representações rivalizam com as representações hegemônicas e, assim, observa-se uma mudança no discurso sobre essa área por parte dos grupos que detêm o poder - empresários, políticos, investidores, grupos imobiliários, agências

\footnotetext{
${ }^{1}$ Doutorando em Geografia na Universidade do Estado do Rio de Janeiro; sua pesquisa se intitula "A urbanização desurbanizada e o uso estetizado do solo em Nova Iguaçu". E-mail: everaldogeo@hotmail.com
} 


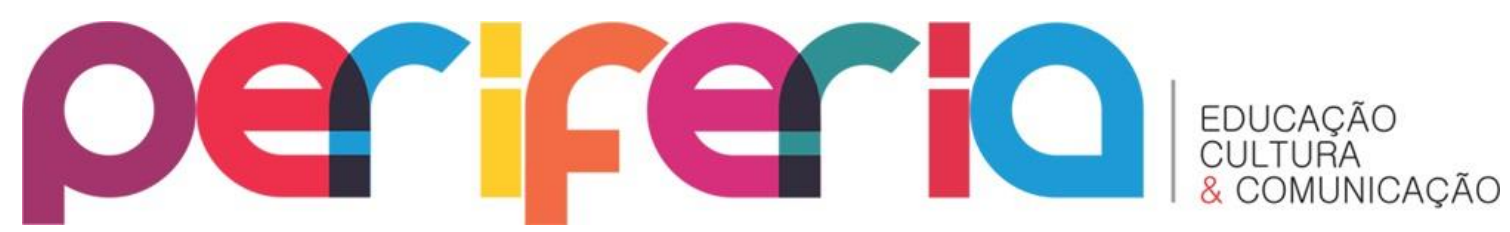

de turismo, dentre outros, que, atentos às novas oportunidades do mercado, objetivam atrair novos investimentos.

O novo discurso promovido por distintos agentes relega a plano secundário a imagem da cidade como lócus de segmentos de baixa renda, precárias condições de infraestrutura e mazelas sociais diversas ${ }^{2}$ e realça as qualidades locais, vendendo a imagem de uma nova cidade onde estão presentes novas formas de morar, de consumo e de lazer, promovendo uma requalificação parcial.

Diante do exposto, este artigo se desenvolve a partir da leitura relacional das categorias de discurso e poder tendo como objetivo analisar, em diferentes períodos da história do município, as relações de poder e as representações sobre a cidade de Nova Iguaçu. Assim, apresentamos os seguintes questionamentos: como o discurso e os mapas ajudam na construção da imagem local? Como o discurso promovido pelos agentes imobiliários vendeu a imagem da cidade no período da citricultura e vende no momento atual?

Este trabalho apresenta três seções. Inicialmente, teceremos uma breve abordagem da relação existente entre discurso e poder. Posteriormente, trataremos dos períodos da citricultura e os seus impactos para a cidade, a "febre imobiliária" e a captura do município de Nova Iguaçu pela metrópole, momento em que a paisagem rural dá lugar aos loteamentos, e o período pós-anos 1980, quando a cidade vivencia a chegada de novos empreendimentos imobiliários e serviços qualificados, que promovem metamorfoses espaciais e requalificam esse espaço. Por fim, analisaremos as representações a respeito da cidade de Nova Iguaçu em dois mapas que destacam dois períodos: a citricultura, na década de 1930, e o momento atual.

\section{O DISCURSO E O PODER: BREVES APONTAMENTOS}

O discurso está na ordem das leis (...) e que, se the ocorre ter algum poder, é de nós, só de nós, que ele lhe advém (...). Mas, o que há, enfim, de tão perigoso no fato de as pessoas falarem e de seus

\footnotetext{
${ }^{2}$ Esta representação ganhou maior evidência no período posterior à crise da citricultura e à explosão dos loteamentos populares, quando a cidade de Nova Iguaçu foi incorporada à expansão da metrópole. No entanto, esse processo não foi acompanhado da implantação de recursos urbanísticos.
} 


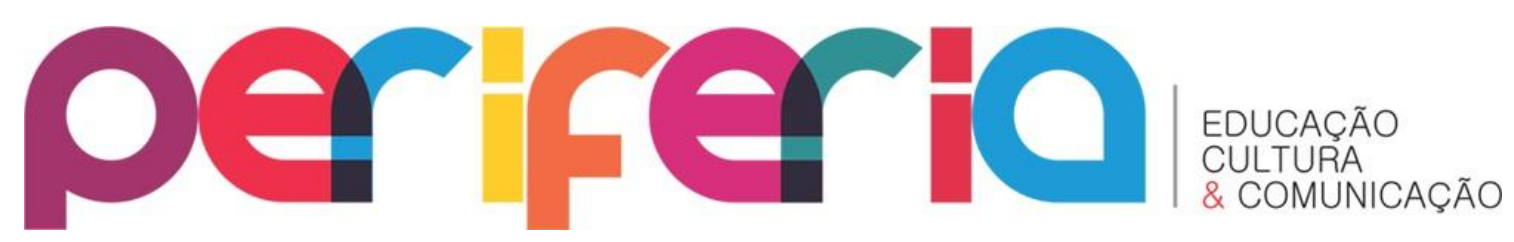

discursos proliferarem indefinidamente? Onde, afinal está o perigo? (FOUCAULT, 2012, p. 7-8).

Os termos discurso e poder apresentam diversas acepções; são polissêmicos, ambíguos, têm grande complexidade conceitual, pluridisciplinar, atraem múltiplos olhares - de geógrafos, historiadores, linguistas, sociólogos, políticos, publicitários e psicólogos sociais, dentre outros. Nesse sentido, o discurso é uma prática social, circunstancial, amplamente discutida por diferentes segmentos sociais, econômicos e políticos. Está intimamente conectada às relações de poder, constituindo-se, deste modo, como algo temerário.

Gill (2002, p. 247) indica que o termo discurso "é empregado para se referir a todas as formas de fala e textos, seja quando ocorre naturalmente nas conversações, como quando é apresentado como material de entrevistas, ou textos escritos de todo tipo". Prossegue a referida autora (p. 248) destacando que "as pessoas empregam o discurso para fazer coisas - para acusar, para pedir desculpas, para se apresentar de uma maneira aceitável".

Dentro da perspectiva linguística, Orlandi (2005, p. 15) destaca que

[...] a palavra discurso, etimologicamente, tem em si a ideia de curso, de percurso, de correr por, de movimento. O discurso é, assim, palavra em movimento, prática de linguagem: com o estudo do discurso observa-se o homem falando.

Participando desse debate, Foucault (2012, p. 10) afirma que "o discurso não é simplesmente aquilo que traduz as lutas ou os sistemas de dominação, mas aquilo por que, pelo que se luta, o poder do qual nos queremos apoderar". Sendo algo construído, selecionado, pois nem todos participam desse processo, organizado, carregado de desejos e intencionalidades, o discurso é apropriado por diferentes segmentos que desejam o poder, pois, "por mais que o discurso seja aparentemente bem pouca coisa, as interdições que o atingem revelam logo, rapidamente, sua ligação com o desejo e com o poder" (idem, p. 09-10).

Assim, os termos discurso e poder dialogam entre si, compondo uma relação simbiótica. O discurso é algo que não é neutro nem transparente; fortalece, por seus 


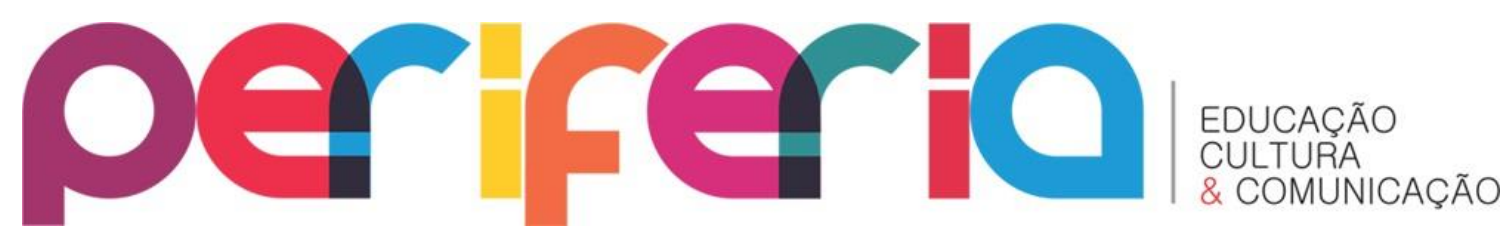

símbolos $^{3}$, as relações de poder - assimétricas/desiguais, sendo elemento fundamental para uma melhor compreensão da produção e organização do espaço, das tensões e conflitos presentes nos territórios, marcados por inúmeras disputas entre os diversos agentes que atuam no processo anteriormente destacado.

Segundo Corrêa (2011), a produção do espaço urbano é caracterizada pela atuação de múltiplos agentes sociais - proprietários dos meios de produção, proprietários fundiários, promotores imobiliários, Estado e os grupos sociais excluídos - que apresentam ações, práticas e estratégias distintas, ora em relações harmoniosas, ora gerando conflitos.

No caso do espaço urbano de Nova Iguaçu, o período posterior à citricultura é marcado pela ação de múltiplos agentes que promoveram a transformação do solo da cidade. Vários proprietários fundiários atuaram em diversas funções nesse processo comercialização dos lotes de terra, implantação de infraestrutura, serviços de cartório, dentre outros (SANTOS, 1995). No cenário contemporâneo, as grandes e médias construtoras - Gafisa, RJZ/Cyrella, Klabin Segall, Nicoll e Agra, entre outras substituíram as pequenas empresas loteadoras, algumas criadas por antigos citricultores que atuaram no período posterior à citricultura.

Assim, o poder deve ser exercido produzindo imagens e representações que façam crer no discurso citado. A respeito do conceito de poder, Raffestin (1980, p. 53) ensina que

[...] o poder se manifesta por ocasião da relação. É um processo de troca ou comunicação quando, na relação que se estabelece, os dois polos fazem face um ao outro ou se confrontam. As forças de que

\footnotetext{
${ }^{3}$ Os símbolos criados preservam valores históricos, memórias e reminiscências de outros períodos. No caso específico da cidade de Nova Iguaçu, há um conflito entre as famílias tradicionais e o migrante nordestino. Para a elite remanescente do período da citricultura, ainda permanecem as memórias do perfume florido dos laranjais, a ideia de uma cidade idealizada manchada com a presença dos 'de fora', aspecto que se expressa inclusive nas campanhas políticas quando presenciamos a presença de faixas com os seguintes dizeres: "Candidato de fora. Tô fora!". Assim, observa-se uma oposição entre a "Terra dos Laranjais' e a 'Cidade dos Loteamentos', entre famílias tradicionais, iguaçuanos, moradores antigos e os pessoal de fora (SOUZA, 1992). Desse modo, observa-se que a íntima relação entre o discurso e o poder difunde e impõe aos mais fracos - os migrantes nordestinos - a responsabilidade pela destruição da cidade ideal, nesse momento manchada pelos graves problemas sociais trazidos pelos de fora.
} 


\section{periferio}

dispõem os dois parceiros (caso mais simples) criam um campo: o campo do poder.

Marcado pelas relações e assimetrias na produção do espaço, o poder é sempre intencional, gerando, dessa forma, inúmeros conflitos entre diversos agentes que o compõem. Diante do exposto, a disputa por investimentos em distintas escalas - local, regional, nacional e global - acirra a disputa e gera a "guerra dos lugares" (SANTOS, 2002). Com efeito, os sentidos das representações contidos em folders, mapas e mesmo no discurso revelam-se como estratégias de poder que, no caso de Nova Iguaçu, se traduz na venda do espaço da cidade.

Nesse contexto, o cenário é evidenciado diante de um leilão de cidade em que se oferece uma série de vantagens - significativo mercado consumidor, a passagem do Arco Metropolitano, terras baratas e proximidade da metrópole, somados à redução de ICMS e oferta de serviços qualificados, entre outras, para atrair investimentos de empresas de grande porte com o intuito de aquecer a economia local. Os investimentos e as novas dinâmicas econômicas promovem uma reorganização econômica da Baixada Fluminense.

Esses investimentos, no entanto, não se distribuem homogeneamente pela região, estando polarizados nos municípios de Duque de Caxias e Nova Iguaçu, que disputam os investimentos oriundos da esfera pública e do capital privado. $\mathrm{O}$ aspecto em tela revela uma tendência à descentralização dos investimentos para os municípios do entorno e para os mais afastados. Simões (2011, p. 183) assevera que

Nova Iguaçu e Duque de Caxias cumprem o papel de cidade externas emergentes no contexto da Região Metropolitana do Rio de Janeiro, cada qual com sua área de influência regional bem definida e com papel econômico, social e político bem consolidado no cenário metropolitano.

Esses municípios apresentam inúmeras vantagens - presença de universidades públicas e privadas, grande mercado consumidor, classe média consolidada, oferta de serviços qualificados, infraestrutura, cortados por rodovias federais e proximidade da metrópole, entre outros, atendendo em parte às exigências da economia global. 


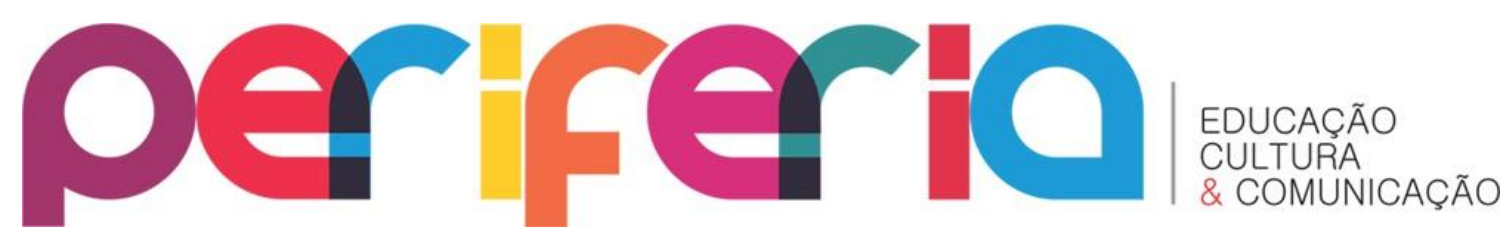

Diante disso, destacamos que o discurso e o poder produzidos por lideranças políticas locais e agentes hegemônicos estão presentes nas disputas por investimentos entre os diversos municípios que compõem a Baixada Fluminense, tendo como objetivo o aquecimento da economia e a geração de empregos, implicando, desse modo, a concentração de poder de determinados grupos políticos, isoladamente ou por meio de alianças políticas que se perpetuam no poder diretamente ou via familiares que disputam cargos públicos como vereadores, prefeitos e deputados, dentre outros.

\section{DOS LARANJAIS E LOTEAMENTOS AOS CONDOMÍNIOS FECHADOS: AS METAMORFOSES SOCIOESPACIAIS NO MUNICÍPIO DE NOVA IGUAÇU}

O final do século XIX caracterizou-se por grandes transformações no município de Nova Iguaçu, com o declínio das atividades agrícolas e a mudança do poder político e econômico da pequena Vila de Iguassú para Maxambomba, dentre outras, sinalizando novo rearranjo espacial. Simões (2011, p. 135) afirma que

[...] a construção da parada de trem em Maxambomba vai ser o marco fundador do atual núcleo urbano (...). Paralelamente, a crise da Vila de Iguaçu após a epidemia de cólera de 1855 transfere parte da população desta para Maxambomba.

É nesse contexto de crise econômica e transformações políticas e espaciais que a laranja se consolida como atividade econômica no município de Nova Iguaçu, sendo apoiada pela política do governo estadual que buscava uma nova fonte de riqueza que pudesse substituir a cana e o café. Para Souza (1992, p. 52), "no início da República, a citricultura surgia como uma atividade promissora, dentro de um quadro de expectativas, por parte dos setores da política do Estado do Rio de Janeiro, de revitalização da agricultura na Baixada Fluminense", posto que "quase toda matériaprima e gêneros alimentícios eram importados por inexistir uma agricultura mercantil, um cinturão de abastecimento local, dada a decadência rural" (LIMONAD, apud SIMÕES, 2011, p. 110). 


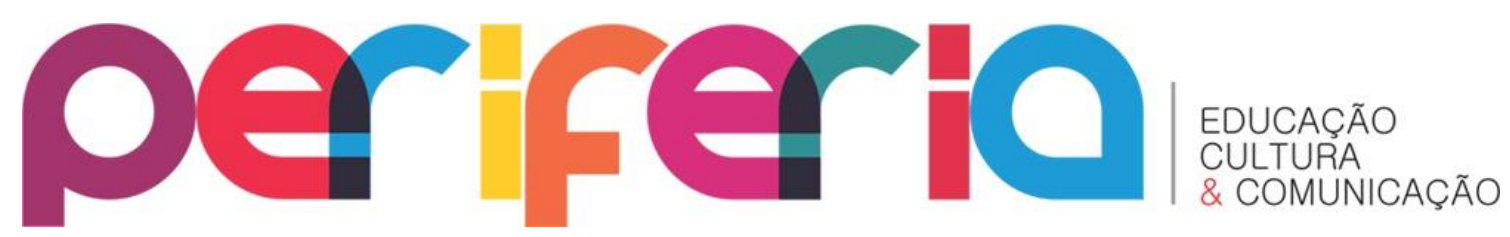

Neste novo cenário, os laranjais encontram condições favoráveis para a sua expansão em terras iguaçuanas recobrindo grandes extensões de terras nas inúmeras chácaras do município beneficiadas por condições naturais e socioeconômicas - clima quente e úmido, fracionamento das terras em chácaras, colinas, tradicionalismo de famílias de origem rural (PACHECO, 1984; PEREIRA, 1977; SANTOS, 1995; SIMÕES, 2011; SOARES, 1962).

Com efeito, os laranjais se expandem pelo município e promovem a cidade no quadro nacional e internacional com a produção destinada a São Paulo e, principalmente, para o mercado externo - Espanha, Argentina, Suécia e Itália, entre outros. Dessa forma, a cidade ganha fama internacional e fica conhecida como "Terra dos Laranjais", "Cidade dos Pomos de Ouro", "Cidade Perfumada".

Diante do crescimento da citricultura e da exportação da produção, emerge uma nova classe social: os laranjeiros, que ocupavam uma área próxima à estação ferroviária ${ }^{4}$, no trecho inicial da encosta da Serra de Madureira, onde construíam residências luxuosas e bangalôs que se destacavam no cenário interno formando uma classe média local oriunda da exportação da laranja e das indústrias de pequeno porte relacionadas à citricultura. Ao analisar a ocupação desta área, Soares (1962, p. 234) destaca que,

[...] nessas encostas de declive forte, onde ainda se vislumbram restos dos belos laranjais que a recobriam, foram abertos vários loteamentos. Devido à hostilidade, tais espaços só foram loteados nos últimos anos, quando as vantagens de sua proximidade do 'centro' e da estação de trem colocaram em segundo plano as desvantagens para loteadores e compradores decorrentes da topografia. Ruas foram abertas serpenteando pelas encostas e esses loteamentos logo se povoaram de pequenas casas.

\footnotetext{
${ }^{4}$ A área em destaque configurou-se depois como embrião do Centro Novo, onde se concentram atualmente os segmentos de alta renda de Nova Iguaçu. Esse aspecto sinaliza um processo de continuidade do espaço elitizado da cidade, desconstruindo a ideia de revitalização dessa área.
} 


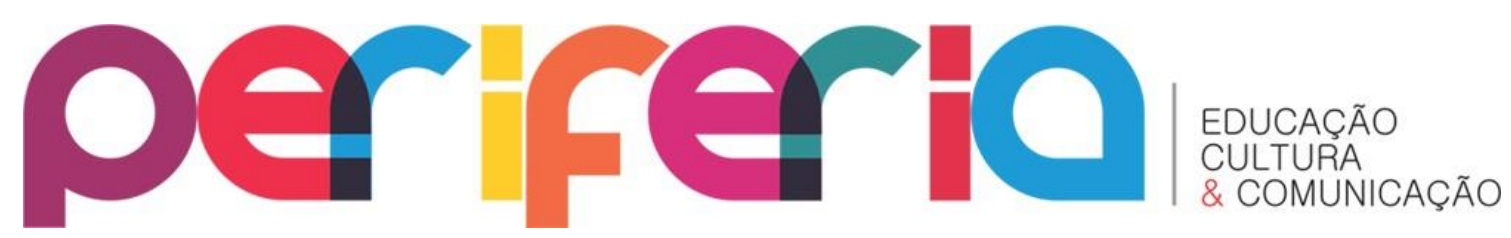

Esse período simbolizou, no imaginário da elite local ${ }^{5}$ e das famílias tradicionais, um período de crescimento da cidade, com a chegada de investimentos: inauguração de 14 novas estradas, criação do serviço de Saneamento da Baixada Fluminense, tração elétrica da Estrada de Ferro D. Pedro II, instalação dos primeiros estabelecimentos bancários e oferta de serviços de venda de automóveis luxuosos (ver Figura 1), dentre outros. A crise da citricultura, no entanto, estava próxima, motivada pela Segunda Guerra Mundial, a mosca do mediterrâneo e a expansão urbana da metrópole carioca, que gradativamente incorporava os municípios ao seu entorno por meio do fracionamento das terras, destinadas aos segmentos de baixa renda.

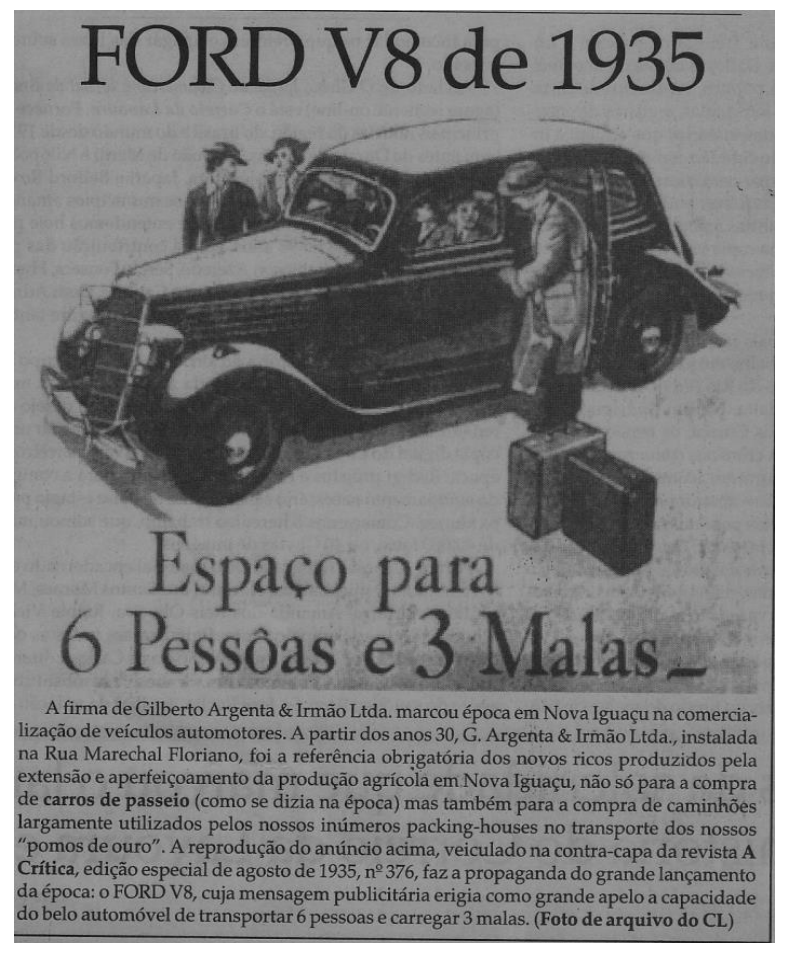

Figura 1: Anúncio de veículo destinado aos novos ricos iguaçuanos no auge do período da citricultura.

Os loteamentos, desse modo, despontam como solução para a grave crise econômica que assolou Nova Iguaçu e a Baixada Fluminense e transformou extensas áreas rurais em áreas urbanas, deixando na retaguarda o passado de atividades agrícolas e a imagem da cidade: "de duas ruas marginando a ferrovia, totalmente

\footnotetext{
${ }^{5}$ A elite local se destacava também por hábitos de consumo de produtos de luxo, pois "era elegante fazer compras no Distrito Federal e até mesmo no exterior, havendo casos de enxovais para batizados e casamentos comprados diretamente na França" (PEREIRA, 1977, p. 143).
} 


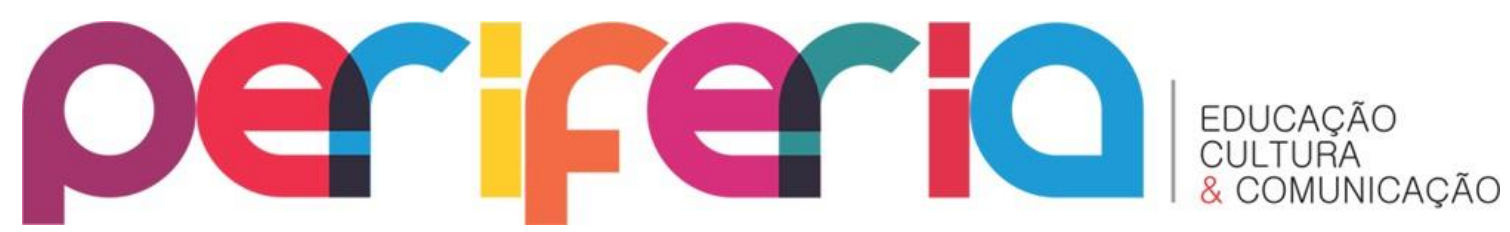

cercada de laranjais" (SOARES, 1962, p. 212). Nesse momento desapareceram os laranjais floridos, substituídos pela febre dos loteamentos, o novo 'eldorado' da economia iguaçuana.

Esses loteamentos irão eclodir e se expandir pelas terras da Baixada Fluminense sendo comercializados "para fins de instalação de indústrias, residenciais ou para construção de avenidas, que depois iam sendo vendidas ou até mesmo alugadas com a finalidade de se extrair renda" (SANTOS, 1995, p. 34). Pacheco apresenta este quadro na região:

[...] alguns citricultores, não mais acreditando na laranja como força econômica, trataram de preservar o capital investido na citricultura, transformando os laranjais em carvão para gasogênio e depois em loteamento. Chácaras inteiras foram, então, parceladas em pequenos lotes com fins residenciais para a venda direta ou para construção e vendas ou aluguel de casas, sendo este o primeiro passo em direção à febre de loteamentos que tomou lugar no pós-guerra como solução para a crise financeira (1984, p. 31).

Ao analisar esse fenômeno e o processo de integração de Nova Iguaçu à metrópole, Abreu (1987, p. 121) afirma que,

[...] aberta ao tráfego em 1951, a Rodovia Presidente Dutra foi responsável pela incorporação de diversas áreas à malha urbana carioca (...); os loteamentos residenciais multiplicaram-se nos locais mais afastados do eixo rodoviário, especialmente no distrito sede de Nova Iguaçu, que, não mais contando com a laranja, integrou-se definitivamente à onda urbanizadora que varria a Baixada há mais de uma década.

No período posterior aos anos de 1950, com a explosão dos loteamentos, a cidade se configurou como um importante subcentro regional de comércio e serviços, aparelhado de galerias comerciais e filiais de lojas até então presentes na metrópole, carioca transformando-se em “Capital do subúrbio" (SOARES, 1962), destacando-a no cenário metropolitano apresentando uma convergência de linhas de ônibus, atraindo um elevado número de consumidores e trabalhadores, acolhendo também os segmentos de baixa renda.

Com efeito, nesse quadro, Nova Iguaçu vê redefinido o seu papel no cenário metropolitano, diante da imposição da metrópole carioca sobre o espaço local: acolher 


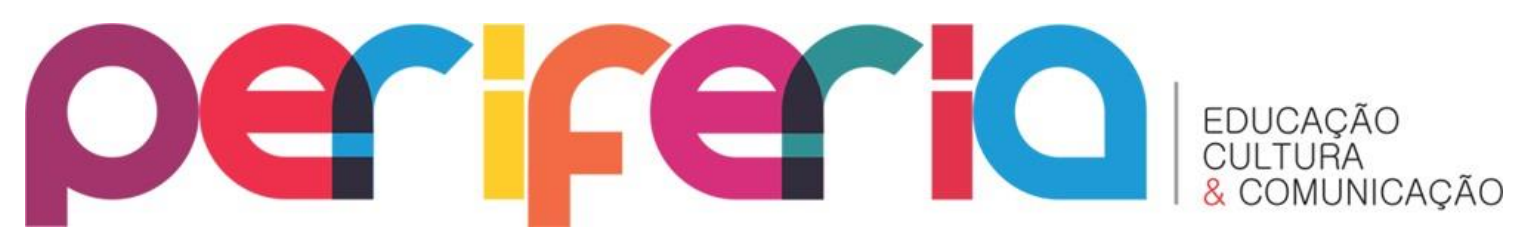

a população de baixa renda e ser integrada na condição de periferia, marcada pela ausência do poder público em suas distintas esferas - municipal, estadual e federal -, carente de infraestrutura, tornando-a conhecida no noticiário local, nacional e internacional como "área de forte criminalidade" (SOUZA, 1992, p. 1), em que a grande maioria das notícias destaca os atos violentos, afugentando, dessa forma, os investimentos.

O processo de expansão do tecido urbano do Rio de Janeiro, capturando novas áreas para o circuito produtivo, não foi acompanhado de benefícios urbanísticos e de infraestrutura - lazer, educação, saneamento básico, transportes e saúde, entre outros, consolidando o espaço periférico em oposição ao centro, que reúne a população de alta renda, a produção, circulação e consumo mais elevado, marcando a estrutura pela dicotomia. Nesse sentido, após o fim dos laranjais em Nova Iguaçu, "o último suspiro agrário" (ALVES, 2003, p. 48) do município e a fase de intensa fragmentação das terras, intensifica-se a urbanização desurbanizada no espaço periférico, refletindo a incapacidade do Estado de dotar essas áreas de bens de consumo coletivo, sinalizando o colapso social da Baixada Fluminense.

Diante disso, emergem as lideranças populares e os movimentos sociais, pelos Movimentos Amigos de Bairros (MABs), que questionam a realidade local, marcada pelas péssimas condições de vida e pelo processo de autoconstrução (SIMÕES, 2007).

No novo cenário econômico que se redefine, a cidade do Rio de Janeiro emerge como "a capital mundial das novas oportunidades", atraindo múltiplos eventos - Jogos Mundiais Militares, Conferência das Nações Unidas sobre Desenvolvimento Sustentável (Rio+20), Copa das Confederações, Jogos Olímpicos e Paralímpicos e Copa do Mundo - e movimentando investimentos e recursos públicos e privados da ordem de R\$ 181,4 bilhões no triênio 2011-2013 (FIRJAN, 2012), confirmando a tradição da cidade de sediar eventos esportivos aquecendo a economia, dando maior visibilidade à cidade e potencializando os investimentos na atividade turística. Esses investimentos se distribuem por distintas regiões do estado e aquecem, dinamizam e promovem novos arranjos na economia estadual. 


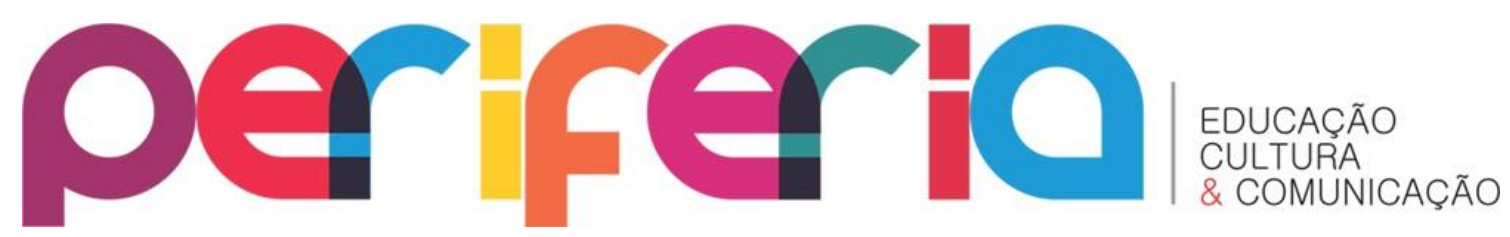

Ao analisar a nova configuração espacial e econômica da Região Metropolitana do Rio de Janeiro, Santos (2003, p. 11-12) afirma que

[...] mudanças também estão ocorrendo na periferia da Região Metropolitana, já que a tradicional dependência em relação ao Rio está diminuindo e o fenômeno da metropolização atinge cidades como Nova Iguaçu, Caxias e São Gonçalo, que vem construindo suas próprias periferias.

Assim, o período posterior aos anos 1980 assinala a retomada do crescimento econômico da Baixada Fluminense, com a chegada de investimentos endógenos e exógenos promovendo metamorfoses na periferia metropolitana do Rio de Janeiro, alterando a visão estática de uma periferia "desvalorizada e condenada à eterna função de espaço dormitório" (FURLANETTO et alii, 1987) caracterizando-se pela modernização dos espaços periféricos. Lago (2010) argumenta, no entanto, que a periferia se constitui atualmente como lugar de trabalho, rompendo desse modo a noção tradicional de "cidade-dormitório", distante do trabalho e com carência de serviços públicos. Segundo Jardim (2007, p. 171), a nova fisionomia desses espaços já podia ser observada nos anos 1970, quando

[...] a periferia metropolitana ganhava novos contornos: aumentava a segregação socioespacial, com a construção de novos condomínios de classe média, cujas demandas de consumo contribuíram para o surgimento de novas áreas cêntricas, valorizadas em função da infraestrutura urbana localizada.

Os anos 2000 ganharam destaque face ao rápido processo de verticalização de Nova Iguaçu, com a presença de condomínios fechados, lojas de decorações, aparthotéis, edifícios de escritórios, polo gastronômico, clínicas de estética, consultórios dentários, casas de festas, lojas de confecções e calçados, dentre outros, valorizando esta fração do solo urbano, que desponta como nova centralidade em Nova Iguaçu. 


\section{periferio}

\section{AS REPRESENTAÇÕES DE NOVA IGUAÇU: DA CIDADE FLORIDA AOS NOVOS EMPRENDIMENTOS IMOBILIÁRIOS}

As representações relacionadas à Baixada Fluminense ${ }^{6}$ quase sempre estão associadas à precariedade de infraestrutura, aos elevados índices de violência e ao abandono das áreas sociais, apontadas anteriormente, com destaque para a área de saúde e educação, por parte do estado em distintas esferas - federal, estadual e municipal. Diante desse cenário, é reforçado no imaginário popular, por múltiplos discursos, um quadro de abandono e atraso no plano político, social e cultural que deixa para trás as potencialidades ${ }^{7}$ econômicas da região.

Assim, o discurso fomentado em mapas ganha destaque no imaginário popular por meio de símbolos que estigmatizam a região. Sendo uma construção social, a partir de imagens produzidas em distintos discursos, em que estão entrelaçadas relações de poder, construiu-se a imagem em tela "mas não é fácil imaginar. Não se imagina no vazio e com base em nada" (ANDERSON, 2008, p. 17).

Com efeito, os mapas, pelos discursos, criam novas geografias, manipulando dados e informações, criando uma falsa imagem da localidade. Diante do exposto, as representações cartográficas jornalísticas a respeito da Baixada Fluminense são bastante raras em jornais e revistas. Os jornais de maior circulação no Estado do Rio de Janeiro - O Globo, O Dia e Extra - atualmente apresentam nos finais de semana cadernos dedicados a essa área, destacando notícias relacionadas às potencialidades e ao crescimento econômico.

Assim, a Figura 2, um mapa publicado pelo Jornal do Brasil em 1938, destaca a valorização das terras em Nova Iguaçu diante da expansão dos laranjais. A

\footnotetext{
${ }^{6}$ A delimitação a respeito dessa área sempre apresentou grande complexidade conceitual, ora estando associada "às semelhanças geográficas entre o litoral e a serra do mar" (OLIVEIRA, 2004, p.18), ora às potencialidades econômicas e aos loteamentos que se intensificaram no período pós-citricultura. Simões (2004, p. 48), a respeito da tentativa de delimitação da região, ensina que "geopoliticamente este é um termo que cada vez mais se identifica com a área original do antigo município de Iguaçu, nome oficial de Nova Iguaçu até $1916 "$.

${ }^{7}$ Entre essas potencialidades mencionamos o turismo, em suas múltiplas variedades - ecológico, histórico, cultural, religioso, dentre outros, com um grande potencial ainda a ser descoberto pelos diversos agentes que atuam nessa atividade econômica.
} 


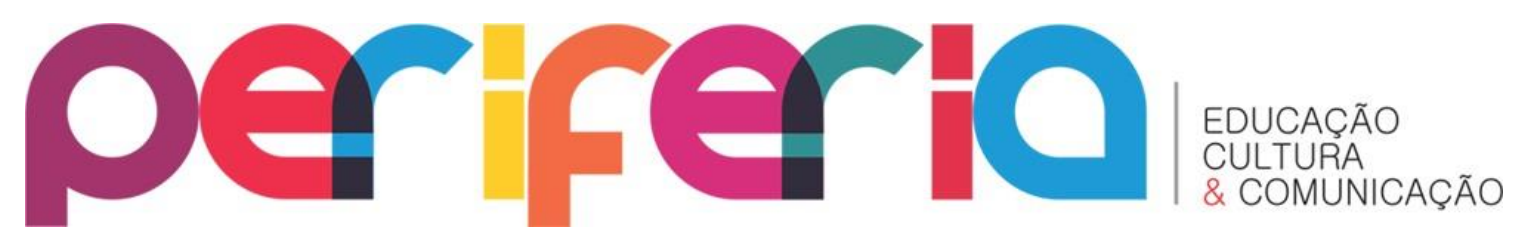

representação ressalta, num plano oblíquo, inúmeros elementos pictóricos eletrificação da via férrea, conectando a estação D. Pedro II à Belém (atual Japeri), as encostas propícias ao cultivo da laranja, a proximidade do Rio de Janeiro, mercado consumidor e investidor, as colinas recobertas por laranjais, a grande extensão e oferta de terras baratas "que valerão ouro".

Essas vantagens são representadas por meio de uma técnica bastante utilizada na reprodução de imagens e mapas na cartografia jornalística: a presença de setas e de um quadro no plano inferior, à esquerda, que atrai a atenção dos potenciais investidores destacando uma rara oportunidade para aquisição de terras na Baixada Fluminense.

A representação parece ser feita à mão, não restringindo a liberdade criativa do autor. A criação dessas imagens demandava tempo, tornando-as raras nos jornais à época. A esse respeito, Novaes (2008, p. 231) afirma que "o tempo para produzir um mapa extremamente simples como esse era relativamente elevado, pois a técnica utilizada acaba determinando a velocidade da produção". No entanto, destacamos a ausência de alguns elementos essenciais na cartografia acadêmica, como a escala e a orientação. Essa ausência acirra um quadro de conflitos entre a cartografia jornalística e a cartografia acadêmica ${ }^{8}$.

\footnotetext{
${ }^{8} \mathrm{O}$ autor prossegue $(2008$, p. 212) afirmando que "a cartografia jornalística sempre foi considerada, na ótica de cartógrafos e geógrafos, uma forma 'inferior' de representação do espaço, já que não respeitava os cânones da cartografia tradicional".
} 

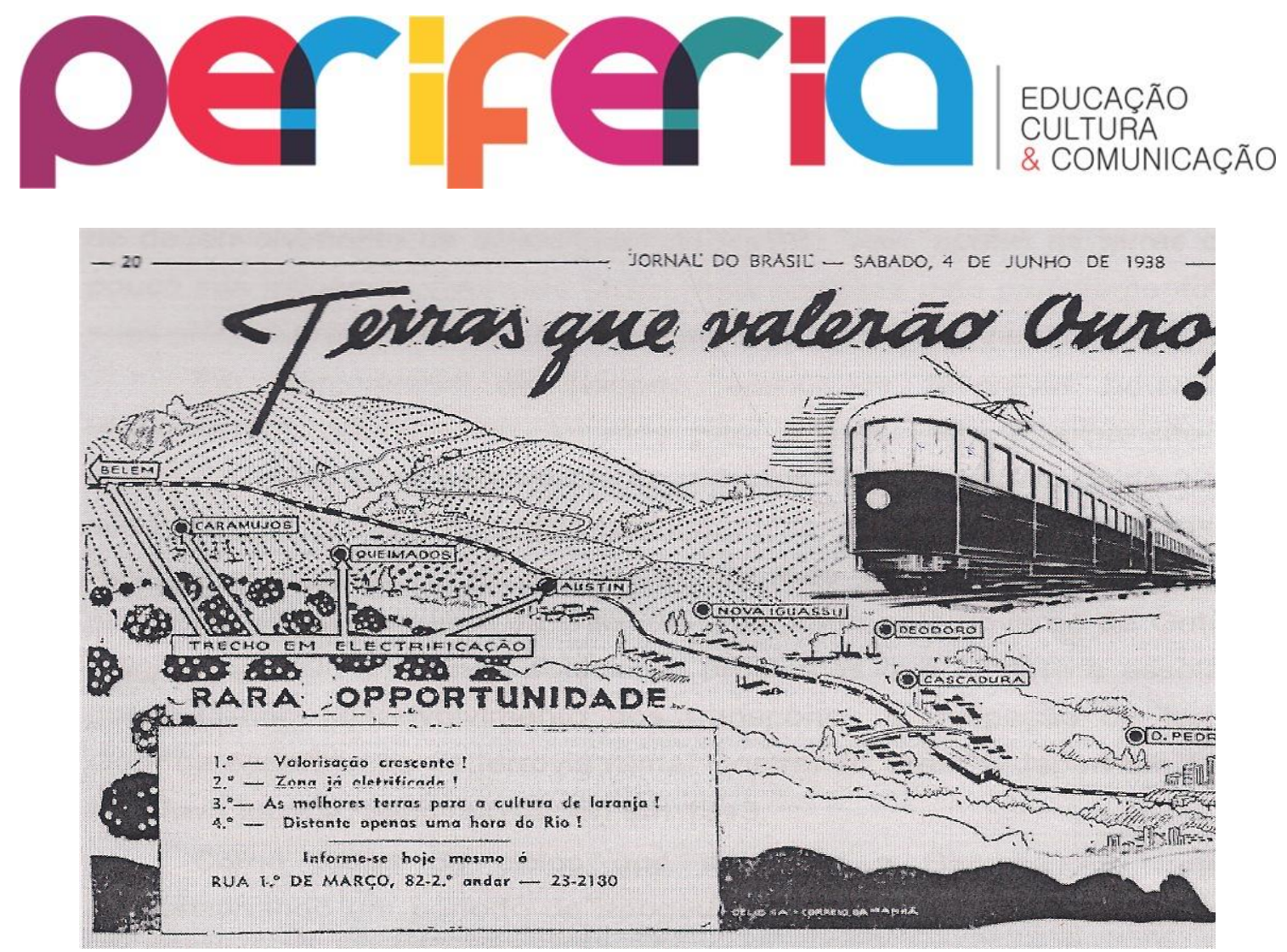

Figura 2: A expansão da metrópole e a valorização das terras na Baixada Fluminense.

A representação seguinte (Figura 3 ) sinaliza um processo de polarização dos condomínios de alta renda no trecho inicial da Estrada Abílio Augusto Távora (antiga Estrada de Madureira). O mapa foi elaborado durante a dissertação de mestrado ${ }^{9}$, com base em uma coletânea de folders distribuídos por corretores e vendedores desses imóveis. De imediato, podemos destacar alguns aspectos: 1) a presença de inúmeros condomínios luxuosos nessa fração do espaço urbano; 2) a polarização de serviços qualificados - restaurantes de luxo, academias de ginástica, lojas de grife, cursos de idiomas, escritórios de arquitetura e de advocacia, dentre outros; 3) a proximidade com a área central da cidade; 4) extensa área verde ao fundo.

Esses elementos funcionam como atrativos para os segmentos de alta renda da cidade que adotam uma nova forma de morar, de lazer e de consumo e um novo estilo de vida (ver Figura 4) que se distanciam do restante da realidade do município. Desse modo, o discurso promovido pelos publicitários tenta "vender seus produtos, estilos

\footnotetext{
${ }^{9}$ A dissertação é intitulada: Reorganização espacial na área central de Nova Iguaçu: o Centro Velho e o Centro Novo (SANTOS, 2008).
} 


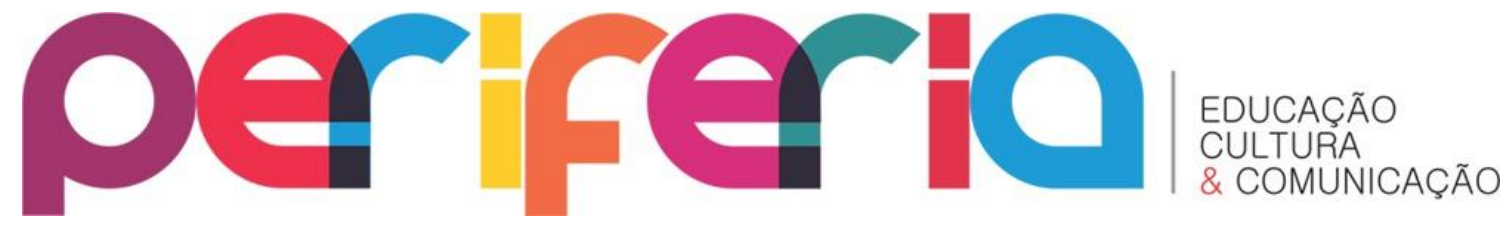

de vida e sonhos" (GILL, 2002, p. 249); assim, a emergência desses novos produtos imobiliários simboliza no imaginário da nova classe média local o ideal de felicidade e de sucesso.

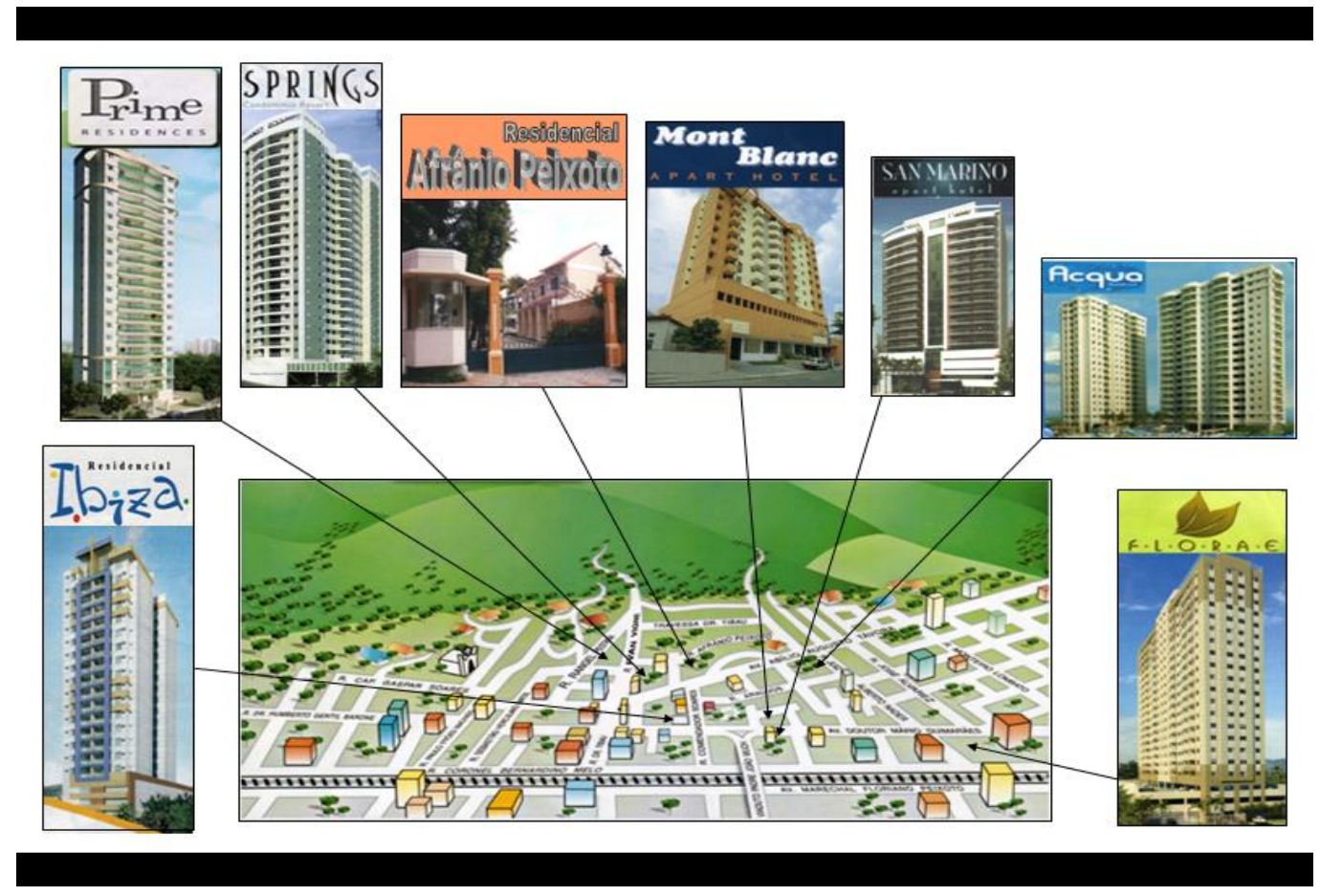

Figura 3: A distribuição espacial dos condomínios e clube-residências na área nobre de Nova Iguaçu.

É importante frisar que, embora ressalte os elementos positivos, o mapa silencia diante dos inúmeros problemas socioambientais presentes na área. Com efeito, o mapa não menciona a crescente onda de sequestros-relâmpago no bairro e, por consequência, a venda de diversos imóveis e a expansão da indústria da segurança que, com cercas elétricas, grades e muros altos, molda a paisagem local; o trânsito caótico nos horários de rush; a poluição sonora e atmosférica; e o processo de ocupação desordenada acelerando o desmatamento, a expansão da economia informal em coexistência com serviços qualificados, dentre outros, sinalizando a existência dos dois circuitos da economia (SANTOS, 2008).

A respeito da omissão/silêncio dos mapas, Harley (apud Novaes, 2008, p. 239) atesta que "a identificação das omissões e dos destaques existentes em um mapa é fundamental para compreender a influência social de algumas práticas que buscam 


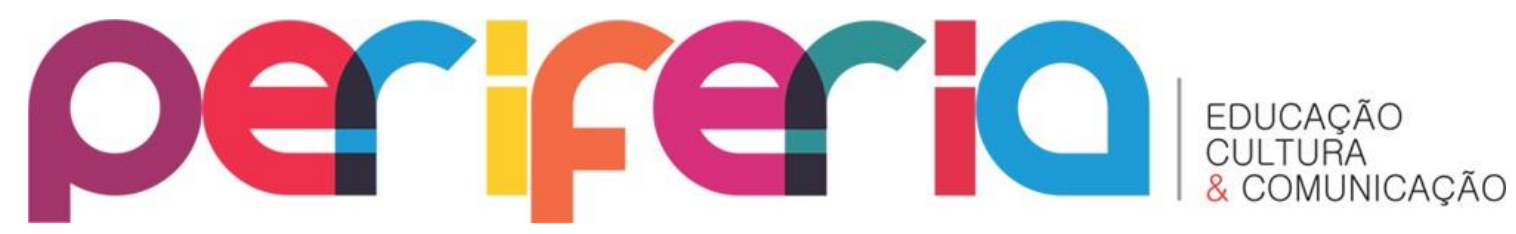

potencializar os efeitos políticos de uma imagem". É interessante frisar novamente a inexistência de escala e de outros elementos cartográficos tradicionais, o que simboliza o caráter de propaganda do mapa.

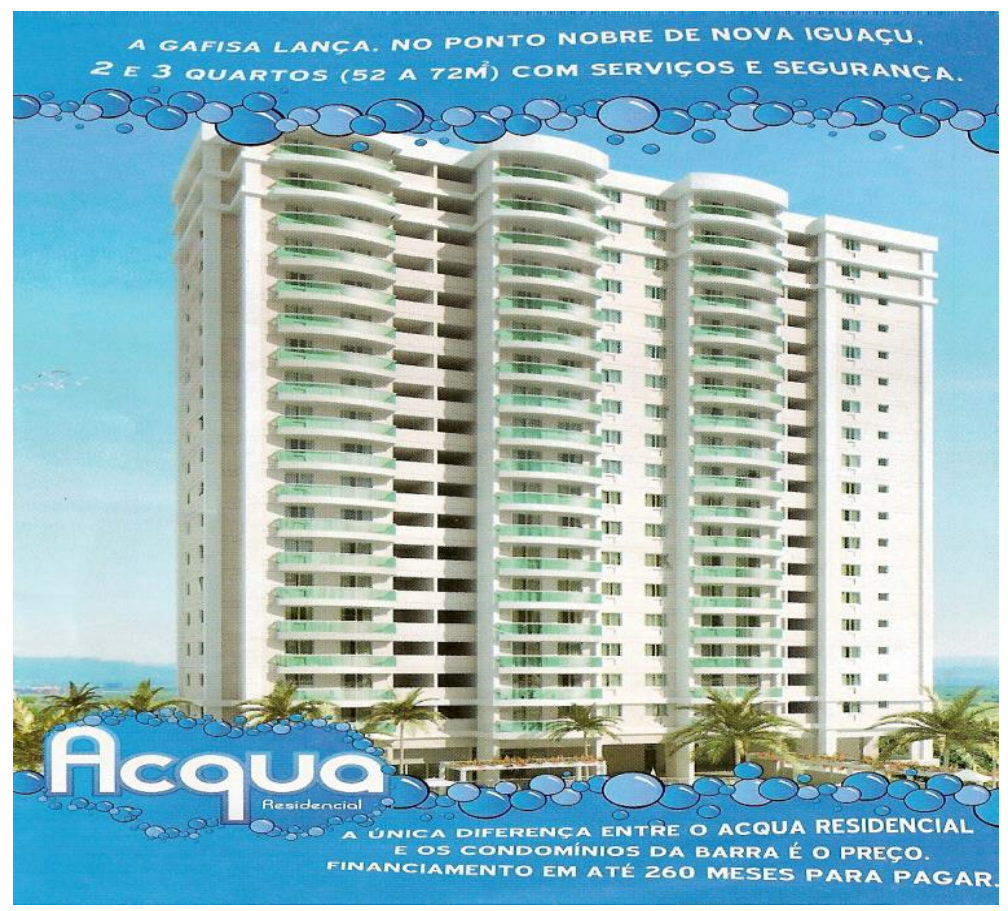

Figura 4: Clube-residência Acqua; destinado à elite local, altera o ambiente construído.

No mapa, é facilmente perceptível o uso de tecnologias que permitem a inclusão de inúmeros símbolos, cores e setas, facilitando a compreensão/manipulação dos aspectos representados. A nova representação da área construída - neste caso, por um discurso cartográfico - atende aos interesses dos proprietários imobiliários, reproduzindo apenas os elementos que esses agentes pretendem destacar no bairro, pois "os mapas são uma abstração do mundo, elaborada a partir de algum ponto de vista" (ACSELRAD, 2008, p. 13).

Essa representação se insere no processo de transformações socioespaciais, a partir dos anos 1980 com a chegada de investimentos endógenos e exógenos, públicos e privados, promovendo uma modernização parcial dessa fração do espaço urbano.

A área, desse modo, sofre um processo de requalificação e deixa, em parte, à retaguarda a imagem de carência em infraestrutura, a homogeneidade social marcada 


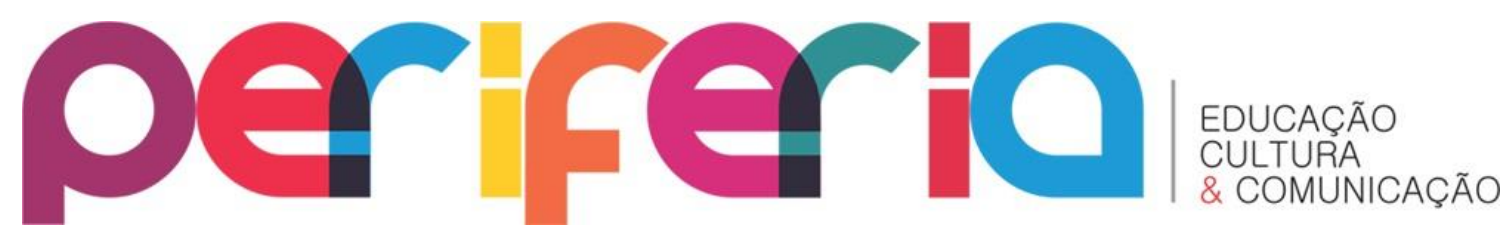

pela pobreza e altera as relações entre a metrópole carioca e a Baixada Fluminense, gerando novos fluxos que impactam a estrutura local. Os espaços periféricos, com destaque para os municípios de Nova Iguaçu e Duque de Caxias, neste momento, despontam na Baixada Fluminense com a chegada de novos empreendimentos imobiliários, a construção de novos shoppings e edifícios comerciais que, na escala local, simbolizam novos signos de consumo ${ }^{10}$ e diante das novas formas promovem um uso estetizado do solo urbano.

Simões (2011, p. 345), ao analisar os lançamentos dos novos produtos imobiliários nessa área, afirma que "os novos lançamentos apostam no padrão 'Barra da Tijuca', em que o oferecimento de serviços, como parques aquáticos, áreas de lazer etc., ocorre associado à redução do tamanho dos apartamentos". Assim, esses condomínios favorecem o isolamento, a segregação espacial e a fragmentação do espaço urbano, opondo "a cidade da minoria burguesa a uma outra cidade: a da maioria pobre" (VILLAÇA, 2001, p. 349). Nesse novo cenário, estão presentes as "ilhas de desenvolvimento", as "privatopias" (HARVEY, 2000); é o valor monetário que determina a possibilidade de acesso a produtos especializados, resultado do medo que põe do lado de fora as classes perigosas e, intramuros, os segmentos exclusivos.

A chegada de novas formas materializadas e polarizadas nessa fração do espaço urbano contrapõe-se às luxuosas residências e bangalôs, reminiscências do período da citricultura, combinando, dessa forma, distintas espacialidades e temporalidades, articulando o presente e o passado no processo de construção e reconstrução da cidade, arrasando os lugares de tempos lentos e substituindo-os pelas novas paisagens (SALGUEIRO, 2003).

Participando deste debate, Pacheco $(1999$, p. 1) afirma que "as novas formas urbanas são visíveis no ambiente construído e encerram um conteúdo igualmente revelador das formas organizacionais do trabalho", produzindo novos rearranjos

\footnotetext{
${ }^{10}$ Este quadro se expressa também diante da chegada das redes de fast food - Bob's, McDonald's, Habib's, Frogs e Outback, dentre outras. Acrescentamos ainda, a migração de lojas, boutiques e joalherias de grife da Zona Sul carioca para Nova Iguaçu sinalizando a mudança no perfil social e econômico presente na cidade.
} 


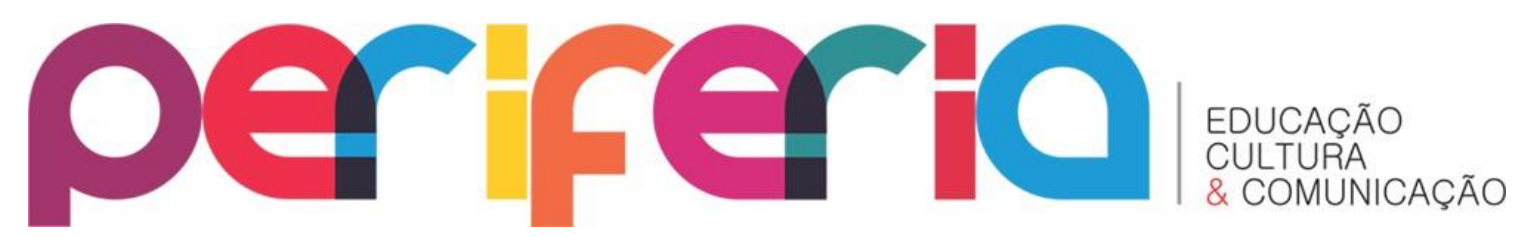

espaciais, sinalizando um processo de modernização do espaço que não se distribui homogeneamente, pois "as diferenças que emergem e se instauram no espaço não provêm do espaço enquanto tal, mas do que nele se instala, reunido, confrontado pela/na realidade urbana" (LEFEBVRE, 2004, p. 117), colocando em oposição o moderno e o tradicional.

O período posterior aos anos 2000 assinala uma fase de rupturas e uma relação de conflito entre o novo e o velho, o moderno e o tradicional, contradições presentes na produção do espaço. As construções de condomínios exclusivos, de cluberesidências e de inúmeros edifícios comerciais - Lumina, Vitally, Apart-Hotel Mercure, Le Monde Office, Centro Empresarial Esther Madeira, Metropolitan Center, Top Comerce Office, Rossi Empresarial e Rossi Diamond e Apart-Hotel Mont Blanc, entre outros, na área central da cidade, redimensionaram o mercado imobiliário local e alteraram o ambiente construído (SANTOS, 2008; SIMÕES, 2011).

Dessa forma, a chegada do novo à cidade alterou as relações de poder preexistentes e estabeleceu novas relações, com a emergência dos novos ricos e de serviços qualificados para atender às exigências da nova classe média local e expulsando para os bairros mais distantes e desprovidos de infraestrutura os mais pobres.

\section{CONSIDERAÇÕES FINAIS}

As relações entre a Cartografia e a Geografia são bastante estreitas, pois os mapas se constituem como elementos fundamentais para consolidar e desconstruir, pelo discurso, novas geografias, reforçando ou alterando as relações de poder em diferentes escalas - local, regional e global. Assim, as imagens e os discursos representados nos mapas, pela Cartografia jornalística, criam no imaginário popular percepções equivocadas de fenômenos geográficos. Essas representações expressas nos mapas, carregadas de valor, sinalizam as intenções de diferentes grupos. Desse modo, os mapas se constituem como importante forma de conhecimento e de poder, 


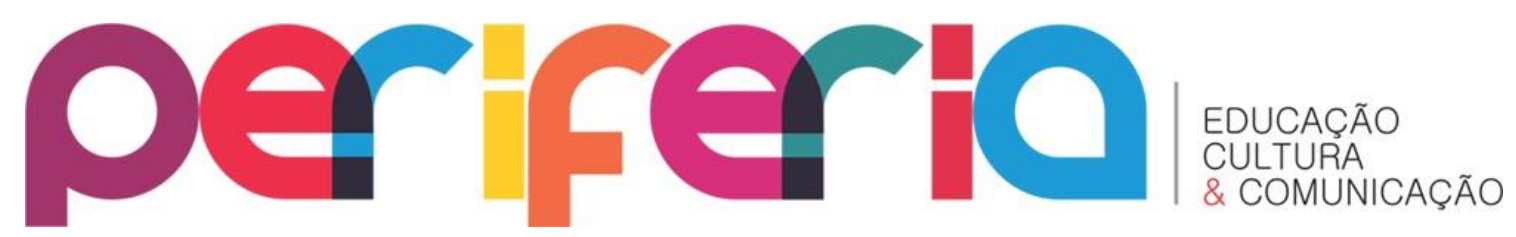

pois expressam o olhar de quem os produziu, atendendo, nos seus silêncios ou na sua "fala", aos interesses dos grupos hegemônicos.

Os mapas analisados, criados na primeira metade do século XX e no início dos anos 2000 como material publicitário, exemplificam as representações a respeito da Baixada Fluminense e do município de Nova Iguaçu.

A produção da Cartografia jornalística apresentava inicialmente uma imagem da cidade de Nova Iguaçu como promissora e com grande potencial econômico para a prática da citricultura, sendo uma boa oportunidade para adquirir grandes extensões de terras baratas. O período posterior, de febre imobiliária, embora não analisado pelas imagens, destaca principalmente no discurso expresso na mídia os elevados índices de criminalidade, em que os noticiários retratam quase sempre as chacinas e os inúmeros grupos de extermínio que atuavam na área.

Com efeito, as representações a partir dos anos de 1980 sinalizam um processo de transformação, com a chegada de novos investimentos; a imagem local ganha destaque como promissora área em desenvolvimento econômico e com grande potencial para o desenvolvimento a atividade turística. Salientamos, no entanto, que, embora construídos/produzidos em distintos períodos históricos, os mapas apresentam aspectos semelhantes ao destacar os elementos atrativos e os seus silêncios para os potenciais investidores. Assim, há sentidos próximos nas intenções dessas representações: possibilitar a venda do espaço da cidade, seja dos lotes seja dos condomínios fechados.

Outro aspecto a ser destacado diz respeito ao caráter de propaganda desses mapas ressaltando as vantagens presentes na área, posto que a comunicação assume caráter persuasivo, direcionada a determinados segmentos econômicos interessados na construção de uma nova imagem, idealizando uma nova cidade nas estratégias de marketing - outdoors, propaganda em jornais e revistas locais e de circulação nacional, anúncios nas rádios e TV, dentre outros, objetivando capturar potenciais compradores.

O "novo discurso" se contrapõe, em parte, à velha representação a respeito de Nova Iguaçu e da Baixada Fluminense, posto pelo interesse do setor imobiliário, das 


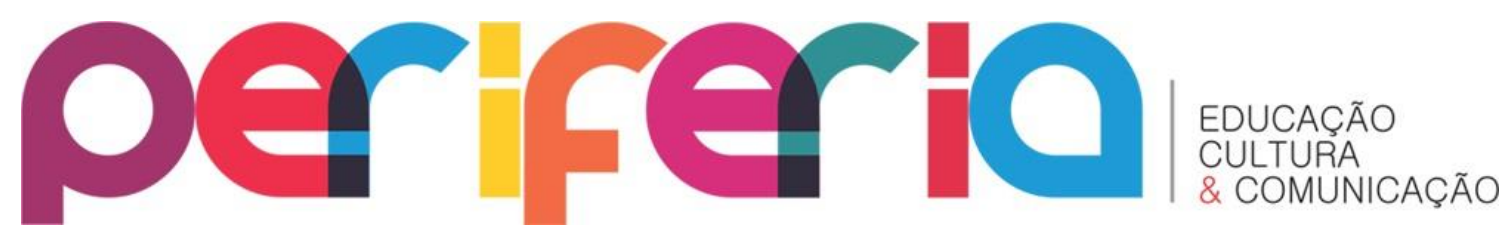

construtoras e das agências publicitárias que procuram produzir uma representação em contraposição à imagem local (ROCHA, 2011) de abandono com novas percepções - novo estilo de vida, possibilidade de novas formas de consumo - alterando em parte a imagem da periferia atrasada do ponto de vista social e econômico que, desta forma, adquire maior complexidade conceitual e maior heterogeneidade socioeconômica.

Dessa forma, acirra-se entre as cidades e os governos municipais a busca por novos investimentos e assim se projetam na mídia impressa inúmeras vantagens para atrair investimentos públicos e privados de empresas que atuam na escala local, regional e nacional. A chegada desses investimentos aquece a economia, promove a requalificação do espaço, altera os arranjos espaciais e as relações de poder em suas múltiplas esferas - política, econômica e cultural.

Por fim, destacamos que as representações da Baixada Fluminense e particularmente de Nova Iguaçu construídas pelos mapas jornalísticos e propagandísticos adquirem aspectos persuasivos, construindo e desconstruindo em seus discursos imagens reais ou simuladas dessa área no imaginário popular, adquirindo, desse modo, caráter ideológico.

\section{REFERÊNCIAS}

ABREU, M. de A. A evolução urbana do Rio de Janeiro. 2a ed. Rio de Janeiro: Zahar, 1987.

ACSELRAD, E. Cartografias sociais e território. Rio de Janeiro: Ed. UFRJ, 2008.

ALVES, J. C. S. Dos barões ao extermínio: uma história da violência na Baixada Fluminense. Duque de Caxias, Rio de Janeiro: APPH, CLIO, 2003.

ANDERSON, B. Comunidades imaginadas: reflexões sobre a origem e a difusão do nacionalismo. São Paulo: Companhia das Letras, 2008.

CORRÊA, R. L. Sobre agentes sociais, escalas e produção do espaço: um texto para discussão. In: CARLOS, A. F. A.; SOUZA, M. L. de; SPOSITO, M. E. B. (orgs.). A produção do espaço urbano: agentes, escalas e desafios. São Paulo: Contexto, 2011. FIRJAN. Decisão Rio, 2012. Disponível em: http://www.firjan.org.br. Acesso em 10 out. 2012.

FOUCAULT, M. A ordem do discurso: aula inaugural no Collège de France, pronunciada em 2 de dezembro de 1970. 22a ed. São Paulo: Loyola, 2012. 


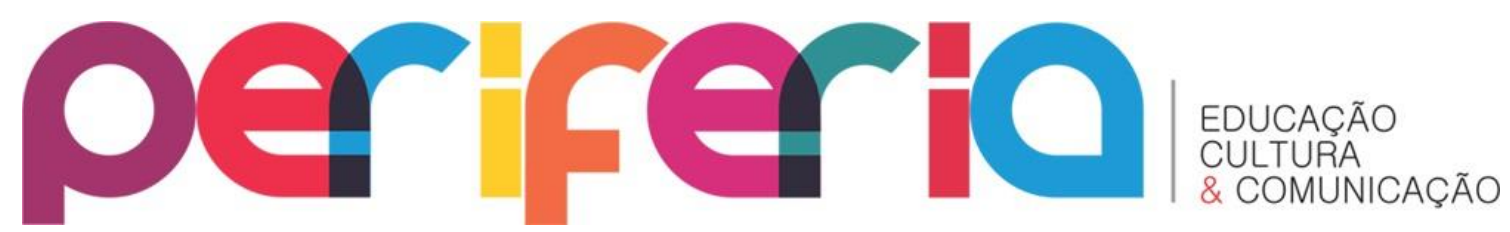

FURLANETTO, D. A. et alii. Promoção imobiliária e espaço residencial da classe média na periferia metropolitana do Rio de Janeiro. Revista Brasileira de Geografia, Rio de Janeiro, IBGE, v. 2, n 49, p. 27-56, 1987.

GILL, R. Análise de discurso. In: BAUER, M. W.; GASKELL, G. (eds.) Pesquisa qualitativa com texto, imagem e som: um manual prático. Petrópolis: Vozes, 2002.

HARVEY, D. Espaços de esperança. São Paulo: Loyola, 2000.

JARDIM, A. de P. Pensando o espaço e o território na metrópole do Rio de Janeiro: refletindo possibilidades analíticas sobre migrações intrametropolitanas. Rio de Janeiro: Ed. do Autor, 2007.

LAGO, L. C. do. A "periferia" metropolitana como lugar de trabalho: da cidadedormitório à cidade-plena. In: SANTOS, A. M. P. (org.). Rio de Janeiro: um olhar socioespacial. Rio de Janeiro: Gramma, 2010.

LEFEBVRE, H. A produção do espaço. Trad. Doralice Barros Pereira e Sérgio Martins (do original: La production de l'espace. $4^{\mathrm{eme}}$ éd. Paris: Anthropos, 2000). Primeira versão: início fev. 2006.

. A revolução urbana. Belo Horizonte, Ed. UFMG, 1999.

NOVAES, A. R. A Cartografia jornalística sobre as drogas ilícitas na imprensa brasileira: omissões e destaques nos mapas jornalísticos. Aurora Geographical, v. 1, p. 39-59, 2008.

OLIVEIRA, R. da S. A relação entre a expansão do município de Nova Iguaçu e os eixos de transporte: algumas considerações. In: OLIVEIRA, Rafael da Silva (org.). Baixada Fluminense: novos estudos e desafios. Rio de Janeiro: Paradigma, 2004.

ORLANDI, E. P. Análise de discurso: princípios e procedimentos. Campinas: Pontes, 2005.

PACHECO, S. M. M. Contrapontos da reestruturação urbana no centro do Rio de Janeiro. Boletim Geter, Rio de Janeiro, ano II, n³ 3, nov. 1999.

. Produção e reprodução de loteamentos na periferia do Rio de Janeiro. Dissertação (Mestrado em Geografia). Programa de Pós-Graduação em Geografia, UFRJ. Rio de Janeiro, 1984.

PEREIRA, W. Cana, café e laranja: história econômica de Nova Iguaçu. Rio de Janeiro: Editora FGV, 1977.

RAFFESTIN, C. Por uma Geografia do poder. Rio de Janeiro: Ática, 1980.

ROCHA, A. S. A representação "ideal" de um território: exemplificando a Baixada Fluminense. Revista Pilares da História, ano 10, no 11, p. 20-30, maio 2011.

SALGUEIRO, T. B. Cidade pós-moderna: espaço fragmentado. Território/LAGET, Rio de Janeiro, ano III, n 4, p. 39-53, jan./jun. 1998.

SANTOS, E. L. dos. Reorganização espacial na área central de Nova Iguaçu: o Centro Velho e o Centro Novo. Dissertação (Mestrado em Geografia). Instituto de Geociências, UERJ. Rio de Janeiro, 2008.

A transformação do capital fundiário em capital imobiliário na Estrada de

Madureira: Município de Nova Iguaçu. Monografia (Graduação em Geografia). Instituto de Geociências, UERJ. Rio de Janeiro, 1995. 


\section{periferio}

SANTOS, A. M. P. Economia, espaço e sociedade no Rio de Janeiro. Rio de Janeiro: Editora FGV, 2003.

SANTOS, M. Guerra dos lugares. In: O país distorcido: o Brasil, a globalização e a cidadania. São Paulo: Publifolha, 2002.

SIMÕES, M. R. Ambiente e sociedade na Baixada Fluminense. Mesquita: Entorno, 2011. . A cidade estilhaçada: reestruturação econômica e emancipações municipais na Baixada Fluminense. Mesquita: Entorno, 2007.

SOARES, M. T. S. Nova Iguaçu: absorção de uma célula urbana pelo Grande Rio de Janeiro. Rio de Janeiro: IBGE, 1962.

SOUZA, S. M. de. Da laranja ao lote: transformações sociais em Nova Iguaçu. Dissertação (Mestrado em Antropologia). Programa de Pós-Graduação em Antropologia Social, UFRJ. Rio de Janeiro, 1992.

VILLAÇA, F. Espaço intraurbano no Brasil. São Paulo: Nobel/Fapesp/Lincoln Institute, 2001. 